\title{
Friendster and Publicly Articulated Social Networking
}

\author{
danah michele boyd \\ University of California, Berkeley - Information Management \& Systems \\ 102 South Hall, Berkeley, CA 94720-4600 \\ dmb@sims.berkeley.edu
}

\begin{abstract}
This paper presents ethnographic fieldwork on Friendster, an online dating site utilizing social networks to encourage friend-of-friend connections. I discuss how Friendster applies social theory, how users react to the site, and the tensions that emerge between creator and users when the latter fails to conform to the expectations of the former. By offering this ethnographic piece as an example, I suggest how the HCI community should consider the co-evolution of the social community and the underlying technology.
\end{abstract}

\section{Author Keywords}

Friendster, social networks, configuring users, identity

\section{ACM Classification Keywords \\ H.5.4 Group and Organization Interfaces}

\section{INTRODUCTION}

Many social applications have social networking embedded both implicitly and explicitly in their design. Through features such as Buddylists and Blogrolls, developers and users have recognized the value of social networks. Recently, this implicit networking has evolved into explicit effort as entrepreneurs seek to capitalize on the social networking theory.

Although explicit social networking sites have existed for years (SixDegrees.com), recent commercial interest has resulted in the emergence of multiple new sites dedicated to helping people capitalize on their social networks for jobs (Ryze.com, LinkedIn.com), dating (Friendster.com), recommendations and listings (Tribe.net). While all of these sites are valuable in this domain, Friendster's popularity, press coverage, and diverse usage make it an ideal candidate for studying the value and implications of this phenomenon on the HCI community.

In this paper, I present portions of my ethnographic work on Friendster in order to consider the tensions that emerge between the architect and the site's population. In particular, I emphasize how users have repurposed the technology to present their identity and connect in personally meaningful ways while the architect works to define and regulate acceptable models of use.

\section{REFLEXIVE CONSIDERATIONS}

It is important to note that I have been an active participantobserver amidst both Friendster users and the social networking software creators. I have tracked Friendster through the media and through the viral discussions on mailing lists, blogs and IRC channels I have organized six focus groups of various relevant social groups and have interviewed or surveyed over 200 users on various aspects of their Friendster experience. Via access to $1 / 3$ of the Profiles, I have analyzed thousands of Profiles and run queries on the visible data. While the vast majority of these accounts are located abroad (predominantly in Asia), the majority of my informants have been in the United States and Canada. Furthermore, the majority of my interviews took place before October 2003, although the site continues to grow and attract new relevant social groups.

I have also consulted with or advised many competing companies and I have regularly informed the press of my findings.

In studying Friendster, my primary ethnographic goals are to: 1) understand how people negotiate context when presenting themselves; 2) examine how the network structure of a meme spreads and connects people; 3) determine the issues involved in articulating one's social network as compared to a behavior-driven network.

\section{WHAT IS FRIENDSTER?}

Friendster is a website that allows people to explicitly articulate their social network, present themselves through a Profile (interests and demographics), post public Testimonials about one another, and browse a network of people. Friendster is built on the assumption that friendsof-friends are more likely to be good dates than strangers. The site was built to compete with Match.com and other online dating sites, with social networks as an additional feature. While Milgram argues that everyone is connected through a countable number of connections [5], Friendster only allows you to access those within four degrees. Unlike most dating sites, Friendster encourages users to join even if they are not looking for dates, under the assumption that 
they probably know a wide variety of friends who are looking and, thus, would serve as a meaningful connector and recommender.

Friendster launched its public beta in the fall of 2002. As of early January 2004, the site is still in beta and has amassed over 5 million registered accounts and is still growing. Both mainstream and alternative press have covered the site, yet word of mouth is the dominant entry point for most people. It is important to note that users have a selfish motivation in spreading the meme, as their network grows by doing so. Friendster's population is primarily cluster-driven and users often convince their entire friend group to participate. While Friendster users are typically 20-something, educated city dwellers, their social and sexual interests are quite diverse. As such, they bring vastly different intentions and expectations to the site.

\section{THE VALUE OF THE NETWORK}

Friendster assumes that users will authentically define their identity via their Profile so as to ensure more meaningful connections. Embedded in this is the assumption that users will see the value in connecting to actual Friends. This is a critical assumption because the desired theoretical results rely on the accuracy of this.

Unfortunately, Friendster fails to recognize that publicly articulated social networks and identities are not identical to the private articulation gathered by sociologists. Furthermore, while sociologists have employed various techniques to categorize and weight relationships, people are often unable to do this individually. As shown in Friendster, this architectural difference results in behavior not predicted by the sociological analysis developed on top of observed behavior and protected informants.

Relationship indicators in Friendster are binary: Friend or not. When traversing the network, there is no way to determine what metric was used or what the role or weight of the relationship is. While some people are willing to indicate anyone as Friends, and others stick to a conservative definition, most users tend to list anyone who they know and do not actively dislike. This often means that people are indicated as Friends even though the user does not particularly know or trust the person. In some cases, it is necessary to publicly be-Friend someone simply for political reasons. Sometimes, people connect broadly so that they may see a larger percentage of the network.

Because of this weakness in the system, the weight of a Friend connection is often devalued because trust cannot be guaranteed. Users publicly recognized this by using the term Friendster in everyday conversation to describe one's Friends. Overheard conversations might include statements such as "She's not my friend, but she's my Friendster" and "Did you see that Alex is Drew's Friendster?"

Publicly articulated social networks also disempower the person performing. As the hub of one's social network, power exists in the structural holes that one maintains [3]. By controlling what information flows between different connections, one is able to maintain a significant role in transactions that occur, and thereby control information flow. This is the value of a headhunter or a businesswoman's Rolodex. Even at the simplest levels, people are often uncomfortable with certain groups of friends to be able to reach out and connect with others, or for work colleagues to connect with personal friends. By asking users to articulate and collapse their network in a public way, Friendster is also asking them to give up their status as a social connector, or bridge.

\section{PRESENTATION OF SELF}

A Friendster Profile consists of five primary elements: 1) demographic information; 2) interest and self-description prose; 3) picture(s); 4) Friend listings; 5) Testimonials. While providing both the individual's perspective of self as well as that of their Friends is beneficial, the Profile is still a coarse representation of the individual, which provides a limited and often skewed perspective [2].

The Profile represents how the individual chooses to present their identity at a specific time and with a particular understanding of one's audience. While the audience and the individual evolve over time, one's Friendster Profile is usually stuck in time. Friend and Profile information are rarely updated and people only remove Friends when there is an explosive end to the relationship, as opposed to the more common growing apart. Testimonials are only a tribute of the moment and reflect the same type of language one might see in a high school yearbook.

Fundamentally, context is missing from what one is presenting. On one hand, an individual is constructing a Profile for a potential date. Yet, simultaneously, one must consider all of the friends, colleagues and other relations who might appear on the site. It can be argued that this means an individual will present a more truthful picture, but having to present oneself consistently across connections from various facets of one's life is often less about truth than about social appropriateness [1]. Another argument is that one is simply performing for the public, but in doing so, one obfuscates the quirks that often make one interesting to a potential suitor.

Notably, most users fear the presence of two people on Friendster: boss and mother. Teachers also fear the presence of their students. This articulated concern suggests that users are aware that, in everyday activity they present different information depending on the audience. Given the task of creating a Profile, users elect to present themselves based on how they balance the public/private dimension.

\section{FRIENDSTER AS A SITE OF CONNECTION}

People use Friendster to connect to others for a variety of reasons. Most users begin surfing Friendster by looking for people that they already know, either currently or in the 
past. In doing so, it is assumed that there is value in reconnecting with long lost friends. For some, this is not true. One interviewee removed her account on Friendster when her high school boyfriend contacted her - she "didn't want [the] past dredged up." While these relationships are quite outdated, people often link to these found old Friends, even though they may now have little in common and cannot vouch for one another when friends want to connect.

While the initial Friend search is in order to build one's network, Friendster users regularly search for people out of curiosity. They look up colleagues and other people who exist in their daily lives. Headhunters use the service to track potential employees' personal lives.

Beyond individual connections, groups of people have organized private "elite" clubs and started weekly pub gatherings through Friendster. Anti-Friendster users have connected in rebellion. In one somber situation, a man with a Friendster account passed away in his sleep. His unconnected friends were able to pass on information to one another via the site. Friends of other deceased Friendster users have constructed memorials via the site.

Two users capitalized on their social network. Believing in the value of their network, they decided to auction connections on eBay. In their ads, they promised both Friendster and real-life connections to hipsters, artists, musicians, record labels, etc. One was serious, while the other was simply making a point:

"The 'self' you're packaging on Friendster is a strictly delimited individual - but when I'm selling my network on ebay, the value is determined by my extended self, defined by its relationships and surfaces rather than content - in other words, the true me, in its full, fragmented, postmodern glory, all the more true the instant a dollar value is placed on it!"

Other users have capitalized on the network structure of Friendster. Women advertise their porn sites by attracting potential clientele. One group of users created a network of Fraudster Profiles to deal drugs, using the Bulletin Board to announce "events" - coded cues to indicate the availability of specific drugs.

While most users are just using the site for fun, curiosity and to play with their friends, it is important to note that many are using it for its intended purpose: dating. The majority of dating falls into three categories: hookups, direct pestering and familiar strangers.

Hookups. In all online dating sites, people surf for hookups as well as potential partners. While the implied theory is that friends-of-friends are the most compatible partners, hookups use the network in a different manner. Many user looking for hookups prefer to be three or four degrees away so as to not complicate personal matters. In addition to intown hookups, Friendster users tell me that they also use the site to find hookups when traveling.
Direct Pestering. People often fail to introduce their single friends to one another. By having a public articulation of one's network, it is really easy to look at Friends' Friends and bug the intermediary about potential compatibility. While three and four degrees are often meaningless to people, there is a decent amount of trust in second-degree connections, simply because they can be easily confirmed via a shared connection.

Familiar Strangers. When Milgram coined the term "Familiar Strangers," he was referring to the strangers that one sees regularly, but never connects with [6]. Given additional contexts, an individual is quite likely to approach a familiar stranger. For many, Friendster provides that additional context. In browsing the site, users find people that they often see out. From the Profile, one can guess another's dating status and sexuality as well as interests and connections. Often, this is enough additional information to prompt a user into messaging someone on Friendster or approaching that person offline.

\section{FAKESTERS: BEYOND ACCURACY}

While some users grapple with Profiles and purpose, others circumnavigate the issues by constructing fake personas, otherwise known as "Fakesters." Three forms of Fakesters account for the majority of use:

1) Cultural characters that represent shared reference points with which people might connect (e.g. God, salt, Homer Simpson, George W Bush, and LSD);

2) Community characters that represent external collections of people to help congregate known groups (e.g. Brown University, Burning Man, Black Lesbians and San Francisco);

3) Passing characters meant to be perceived as real (e.g. duplicates of people on the system, representations of friends who refuse to participate). This type of Fakester is sometimes called Fraudsters. One site, Pretendster, automatically generates Friendster accounts.

When creating a Fakester, users go out of their way to be as creative as possible in their Profile. People be-Friend these characters when they appreciate what is represented, value the creativity, or seek to expand their network.

Passing Fakesters are sometimes intended to represent nonparticipants or provide useful services. For example, a group of guys created a fake female character to give them good Testimonials and to introduce them to interesting women. Other passing Fakesters are also created out of spite in order to confuse the network. With multiple representations of a single person, users are often not sure if they are talking to their friend or a fake, but identical, representation of that person. This behavior is often used against exes or other disliked individuals, such as Friendster's "autocratic dictator." 
Reference: boyd, danah. "Friendster and Publicly Articulated Social Networks." Conference on Human Factors and Computing Systems (CHI 2004). Vienna: ACM, April 24-29, 2004.

\section{The Fakester Dilemma}

While Fakesters have been an integral part of Friendster since its inception, the company has never approved of this behavior. As such, they have actively sought to configure their users [4], regardless of the value or reason behind this behavior. The initial argument against Fakesters is that they collapse the network, devaluing the meaning of connections between people on the system. This argument assumes that the network's value is in trusted links and that a Friend of a Fakester is going to be less trustworthy or compatible than the real, but virtually unknown, acquaintance of a friend. It also assumes that the primary use is in searching through the gallery for potential connections.

Most users do not browse via the central searchable index of Profiles; they navigate through Friends' Friends. Thus, they ignore Fakesters if they are not interested. Yet, by and large, most people love the fake characters. They become little hidden treasures in the network and people go seeking out the most creative ones. Fakesters that represent groups allow people to more quickly find one's friends and acquaintances.

Because many users saw value in the Fakesters, a tension formed between the company and the users. The company outraged users by systematically deleting fake Profiles. A group identified as the "Fakester Revolution" formed out of outrage against the "Fakester Genocide." They actively created new Fakesters and tried to muck with the network while the company continued to play whack-a-mole.

While most users did not participate in this endeavor, many of my informants reported that the site became less interesting once the Fakesters were removed. While they recognized why the company might have a problem with the Fakesters, they disagreed with the removal of the Fakesters because they valued the creative expression and the usefulness of community characters.

While many users love Fakesters, they also reflect the fundamental weakness of trust on Friendster. Is anything actually real? Even Community Fakesters do not authenticate that the individual actually belongs and is accepted by the represented community. One user told me that Fakesters were actually great because they reminded him that nothing presented on Friendster is actually real.

\section{LEARNING FROM FRIENDSTER}

Although social software has existed since the beginning of Internet connectivity, new social applications are consistently emerging in the HCI domain. Some of these applications are directed at private social interactions, while some are inherently more public. Friendster is an odd combination; it is the public exhibition of private relationships in order to allow for new private interactions.

The ethnographic results I have presented above reveal tensions that emerge as users participate in a public/private social application with varying expectations, values and experiences. As with many social applications, the Friendster designers constructed a tool with intended usage scenarios only for their users to quickly repurpose the system to meet their needs [7]. Regardless of the targeted goals of the designers and the successful creation of a popular and usable interface, social applications are always vulnerable to the creative energy of their users. Such creativity can often thwart the creators' efforts or otherwise disrupt the system for all involved.

The disruptive capability of users challenges the HCI community when dealing with social applications. While usability and ethnography are tools that we regularly employ to evaluate the success of new developments, we rarely consider how the structure of an HCI application is not only the architecture, but also the social norms and values that emerge through extended use and diverse populations. Doing so requires us to analyze developments iteratively. Furthermore, it challenges designers to consider the extensibility of the usability of their creation.

In analyzing social applications, architectural changes fundamentally alter the ways in which people connect socially. While trying to help people connect, Friendster has uncovered a hornet's nest around articulated public identity, reshaped how groups of people verbally identify relationships, and solidified the importance of creative play in social interaction. My goal is to highlight these lessons so that designers may learn from them and apply them to new iterations of this software.

\section{ACKNOWLEDGMENTS}

Thanks to Peter Lyman for his support, my informants for their stories, and Tribe.net, KRD, and Washington Post for funding the focus groups.

\section{REFERENCES}

1. boyd, d. Faceted Id/entity: Managing Representation in a Digital World. MIT Master's Thesis. Cambridge, MA, August 9, 2002.

2. boyd, d. Sexing the Internet: Reflections on the role of identification in online communities. Sexualities, medias and technologies: theorizing old and new practices. University of Surrey, June 21-22, 2001.

3. Burt, R.S. Structural Holes: The Social Structure of Competition. Harvard University Press, 1995.

4. Grint, K. and Woolgar, S. Configuring the user: inventing new technologies. In Grint \& Woolgar, The machine at work: technology, work, and organization. Cambridge, UK: Polity Press, 1997, 65-94.

5. Milgram, S. The small world problem. Psychology Today, 6 (1967), 1:62-67.

6. Milgram, S. The Familiar Stranger: An Aspect of Urban Anonymity. The Individual in a Social World. AddisonWesley, Reading, MA, 1977. 
Reference: boyd, danah. "Friendster and Publicly Articulated Social Networks." Conference on Human Factors and Computing Systems (CHI 2004). Vienna: ACM, April 24-29, 2004.

7. Morningstar, C. and Farmer, F. The Lessons of Habitat. Cambridge, MA, 1990 In Benedikt, Cyberspace: First Steps. MIT Press. 